ARTÍCULO

\title{
Educación patrimonial y formación inicial docente: aportes desde el rescate y conservación del patrimonio escolar
}

\author{
Lorena López Torres' (D) \\ María Ignacia Castro Rojas' (D) \\ Priscila del Pilar López Villegas' (D)
}

\section{RESUMEN}

Este artículo presenta posibles formas de abordar la educación patrimonial en la Formación Inicial Docente a partir de la revisión del curriculum de la carrera de Pedagogía en Lengua Castellana y Comunicación de la Universidad Católica del Maule, considerando la creación de un archivo histórico en una escuela básica en la ciudad de Talca (región del Maule, Chile). El trabajo de conservación, archivística, investigación histórica y digitalización de los documentos del establecimiento ha significado la incorporación de un grupo de estudiantes universitarios, cuya participación ha despertado una reflexión rica e interesante sobre la necesidad de incorporar nociones de educación patrimonial en la formación docente universitaria. Su inclusión aseguraría una educación integral de los estudiantes, quienes, como ciudadanos, podrían preservar y valorar esta herencia, y enseñar a otros a apreciarla, en tanto experiencia comunitaria y social.

\section{PALABRAS CLAVE}

educación patrimonial; formación inicial docente; archivos escolares; relación escuela-universidad; curriculum.

'Universidad Católica del Maule, Talca, Chile. 


\title{
HERITAGE EDUCATION AND INITIAL TEACHER TRAINING: CONTRIBUTIONS FROM THE RESCUE AND CONSERVATION OF SCHOOL HERITAGE
}

\begin{abstract}
The present article presents possible ways to approach heritage education in Initial Teacher Training based on the revision of the curriculum of the subject Pedagogía en Lengua Castellana y Comunicación, of Universidad Católica del Maule, considering the creation of a historical archive in a primary school in Talca City (Maule región, Chile). The work of conservation, archival, historical research, and digitalization of documents of the establishment meant the incorporation of a group of university students, whose participation has aroused a rich and interesting reflection on the need to incorporate notions of heritage education in university teacher training. The inclusion of the students would ensure an integral education for students, who, as citizens, could preserve and value this heritage, and teach others to appreciate it, both as a community and social experience.
\end{abstract}

\section{KEYWORDS}

heritage education; initial teacher training; school archives; school-university relationship; curriculum.

\section{EDUCAÇÃO PATRIMONIAL E FORMAÇÃO INICIAL DE PROFESSORES: CONTRIBUIÇÕES PARA O RESGATE E CONSERVAÇÃO DO PATRIMÔNIO ESCOLAR}

\section{RESUMO}

O presente artigo apresenta maneiras possíveis para abordar a educação patrimonial na Formação Inicial de Professores, com base na revisão do currículo da matéria Pedagogía en Lengua Castellana y Comunicación da Universidad Católica del Maule, considerando a criação de um arquivo histórico em uma escola básica na cidade de Talca (Região de Maule, Chile). O trabalho de conservação, arquivamento, pesquisa histórica e digitalização dos documentos do estabelecimento significou a incorporação de um grupo de estudantes universitários, cuja participação suscitou uma reflexão rica e interessante sobre a necessidade de incorporar noções de educação patrimonial na formação de professores universitários. Sua inclusão garantiria uma educação integral dos alunos, que, como cidadãos, pudessem preservar e valorizar esse patrimônio e ensinar outros a apreciá-lo, como uma experiência social e comunitária.

\section{PALAVRAS-CHAVE}

educação patrimonial; formação inicial de professores; arquivos escolares; relação escola-universidade; currículo. 
Toda operación científica o pedagógica sobre el patrimonio es un metalenguaje, no hace hablar a las cosas sino que habla de y sobre ellas. (García, 1994, p. 68)

\section{INTRODUCCIÓN}

El interés de esta investigación se enfoca en reflexionar respecto de las posibilidades ofrecidas por la educación orientada al reconocimiento de los elementos materiales e inmateriales propios de una escuela básica y su puesta en valor por parte del estudiantado toda vez que conoce y significa esos bienes. Estas inquietudes surgieron durante la construcción de un Archivo Histórico en una escuela de la ciudad de Talca (Chile), uno de los establecimientos educacionales de raigambre rural más antiguo de la región del Maule, que concentra una población escolar proveniente de El Sauce, Puerta Negras, San Valentín, Ramadilla, Huilquilemu, Purísima, entre otros sectores aledaños.

La investigación fue realizada por el Grupo de Investigación Poliana. Escuela \& Imaginarios ${ }^{1}$ y se circunscribe al nacimiento del Museo Pedagógico del Maule de la Universidad Católica del Maule, que tiene como misión vincular Universidad, Escuela y Comunidad. Esta iniciativa persigue generar en los profesores - con énfasis en los de Formación Inicial Docente (FID) ${ }^{2}$ - un acercamiento al legado del profesorado para salvaguardar su riqueza mnemónica construida en su itinerario educativo de casi dos siglos de historia. Este espacio museal permitirá también un acercamiento al pasado escolar de la región al brindar reconocimiento al quehacer docente de antaño y visibilizar al sujeto escolar y a la escuela en la recuperación de sus memorias.

Los primeros avances en la creación del Archivo Histórico se remontan a comienzos del año académico 2017 y se relacionan directamente con el patrimonio material perteneciente a la escuela: documentos de variada índole, libros de registros e imágenes fotográficas, encontrado en deficiente estado de conservación, lo que favorecía su deterioro. A este se suman los relatos orales y testimonios (entrevistas) de miembros de la comunidad educativa. Ante este panorama nace el Grupo Poliana, que se dedica a rescatar, perseverar, defender y asegurar la trascendencia del patrimonio histórico y, en específico, la memoria histórica de este establecimiento. Sin embargo, nuestro primer horizonte de trabajo, dirigido a la conservación y a la puesta en archivo del patrimonio escolar, se fue ampliando durante el transcurso del

1 Los aportes aquí presentados surgen del trabajo intelectual y de campo llevado a cabo por el Grupo de Investigación Poliana. Escuela \& Imaginarios, formado por once estudiantes y una académica de la Carrera de Pedagogía en Lengua Castellana y Comunicación de la Universidad Católica del Maule (N. de las As.).

2 En 2016 se promulga la Ley no 20.903 que establece los lineamientos de la Formación Inicial Docente (FID) para incrementar su calidad a través del mejoramiento de la formación como parte del Sistema de Desarrollo Profesional Docente (Chile, 2016). 
trabajo, debido a que surgieron nuevos desafíos en torno a otras áreas e intereses a abordar, como la noción de patrimonio cultural y los desafíos de la conservación, las acciones pedagógicas patrimoniales y la atracción de la comunidad educativa hacia la valoración de su patrimonio inmediato. Todo esto decantó en la exploración del campo de la educación patrimonial, que, al mismo tiempo, se mostró al grupo como un ámbito escasamente incorporado al currículum escolar vigente y completamente ausente del plan de estudios de la FID en la Universidad, y en particular, en la carrera de Pedagogía en Lengua Castellana y Comunicación.

Este último punto concentró nuestra atención, ya que crear el archivo ha permitido repensar la labor docente universitaria y los procesos de formación de los estudiantes de la carrera al estimular acercamientos crítico-reflexivos y vislumbrar posibles acciones pedagógicas a través de enfoques interdisciplinarios. En la ejecución del proyecto, se han integrado diferentes conocimientos que han despertado en los estudiantes intereses y preguntas investigativas no solo referentes al pasado, a la memoria y a su conservación, sino también al enorme caudal de otros saberes y experiencias que espera por ser compartido en la escuela y que puede ser valorado desde diversos enfoques. A través de su participación activa en el proyecto, los estudiantes, como futuros docentes, refuerzan su compromiso con la educación y con la sociedad, manifiestan un actuar dinámico y propositivo en la escuela y adquieren herramientas que les permitirán en el futuro, hacerse cargo de cuestiones cruciales en el ámbito de la educación formal. Esto nos permite pensar la integración del patrimonio en la sala de clase, entendida ahora como un espacio multidisciplinario, abierto y rico que recoge y estimula las experiencias de los actores en torno a su propia historia escolar, el derrotero significativo de su memoria y su levantamiento por y para las nuevas generaciones.

En tal sentido, este artículo hará referencia, en primer lugar, a las nociones teóricas que fundamentan nuestro trabajo de investigación enfocado en proponer una perspectiva patrimonial en directa relación con el desarrollo de nuestra labor de rescate y creación del archivo histórico de la escuela. En segundo lugar, al desarrollo de nuestra metodología de trabajo, cómo integramos trabajamos junto a la comunidad escolar de manera colaborativa, así como también la expansión hacia múltiples áreas patrimoniales. Por último, nuestras reflexiones en la exploración de las posibilidades, que por ahora vislumbramos, de fomentar la educación patrimonial con miras hacia su inclusión en la FID en la Universidad, de forma de influir luego de manera positiva en el curriculum nacional, independiente del sector de enseñanza.

\section{NOCIONES DE PATRIMONIO}

La noción de patrimonio varía de acuerdo con la diversidad de comunidades existentes al igual que responde a múltiples dimensiones. Es por esto que este concepto, con su evolución histórica, ha tenido un crecimiento exponencial, cuestión por la cual se hace imposible delimitarlo, pues se ha vuelto polisémico y se observa siempre en vías de construcción (Hernández, 2003).

Desde nuestra óptica, podemos considerar que el concepto de patrimonio se relaciona estrechamente con la necesidad de la permanencia de la memoria en la 
sociedad - y, en nuestro caso específico, la escuela - para la conformación de una identidad, en la que cada colectividad intenta formar su propia cultura, determinada por ciertos fenómenos sociales, históricos y naturales en un tiempo específico. A partir de esa noción básica, se puede deducir que la noción de patrimonio no se fija solamente en la valoración de los objetos como fin último, sino que en la relevancia que las personas como miembros de una comunidad le dan a esos bienes materiales, los reconocen como propios y los atesorar, identificándose con estos.

En el medio educativo, el intercambio de experiencias, relatos y objetos al que el conjunto de actores se somete, configura la historia y memoria del espacio escolar, contribuye a la comprensión y preservación del patrimonio de la escuela, por medio del cual se lograría consolidar la noción de patrimonio desde su vertiente cultural.

Con este sentido, la Unesco (United Nations for Education, Science and Culture Organization), a través de su Oficina Regional de Educación para América Latina y el Caribe (Unesco, 2017) entrega una definición de Patrimonio Cultural entendida como aquel compuesto no solo "por monumentos y colecciones de objetos en museos, sino que también por expresiones vivas, intangibles o inmateriales heredadas de nuestros antepasados y transmitidas a nuestros descendientes" (Unesco, 2017).

En la Convención sobre la Protección del Patrimonio Mundial, Cultural y Natural de 1972, se señala que los Estados adherentes procurarán estimular en sus pueblos el respeto y la valoración del patrimonio cultural y natural, a través de programas de educación y de información (Matsuura, 2005). De ahí que, en adelante, y en particular, hacia finales del siglo XX, la Unesco concentrará sus esfuerzos por promover la conciencia patrimonial en especial entre los jóvenes a través de diferentes redes y de la propuesta de herramientas didácticas y metodológicas.

Para la valorización y la difusión del patrimonio en las diversas comunidades, esta organización enfatiza en una "dimensión histórica, historiográfica y material" (Fontal, 2003b, p. 23) del patrimonio cultural. La entidad amplía su visión y definición hacia lo inmaterial, espiritual e identitario del patrimonio, incluyendo una visión universalista para indicar el sentido de pertenencia del patrimonio en las comunidades. Es así como el patrimonio cultural hace referencia a la interacción de los diversos bienes, tanto materiales como inmateriales, que conforman la identificación de una cultura en una comunidad determinada, en la cual los actores, que son o que han sido parte de su evolución social, son indispensables para develar el contenido histórico y cultural de la memoria que le pertenece.

Este patrimonio cultural representa una forma de convivencia donde, como propone García (2009, p. 273) “cada individuo se reafirma al ser parte de un grupo donde se identifica y se siente parte en la construcción de una memoria colectiva y sus significados". Al acercar los bienes patrimoniales a los ciudadanos, existirá una complicidad social que implique su participación directa como actores que conforman la comunidad y que se reconocen en ciertos valores culturales. Serán quienes sustenten sus bienes patrimoniales, despertando en sí mismos un sentido de apropiación y respeto hacia su patrimonio local.

A través del tiempo, la Unesco ha trabajado en nuevas convenciones sobre patrimonio cultural en diversos países, conformándose así el World Heritage Centre 
(1992) encargado de plantear la valoración, difusión y conservación del patrimonio mundial, tangible e intangible. En la Convención para la salvaguardia del patrimonio cultural inmaterial de 2003, la entidad expresa que el patrimonio cultural puede concebirse desde una perspectiva inagotable, apelando a

aquellos usos, representaciones, expresiones, conocimientos y técnicas - junto con los instrumentos, objetos, artefactos y espacios culturales que les son inherentes - que las comunidades, los grupos y en algunos casos los individuos reconozcan como parte integrante de su patrimonio cultural. Este patrimonio cultural inmaterial, es recreado constantemente por las comunidades y grupos en función de su entorno, su interacción con la naturaleza y su historia, infundiéndoles un sentimiento de identidad y continuidad y contribuyendo así a promover el respeto de la diversidad cultural y la creatividad humana. (UNESCO, 2003, p. 2)

La noción de patrimonio sigue ampliándose de manera significativa, al entrar en consideración el inagotable poder identitario de este en un determinado contexto histórico, social y cultural. Por una parte, Ibáñez, Fontal y Cuenca (2015) presentan una subdivisión de distintas visiones, entre las que se destacan, la objetual, que se relaciona con aquellas evidencias o elementos tangibles del patrimonio, la monumentalista, que se refiere a los bienes patrimoniales que consten o necesiten gran presencia geográfica y la historicista donde predomina el peso y el valor que una comunidad ha de otorgar a su herencia histórica. Por otra parte, Monfort (2007) propone una visión que hace referencia al patrimonio como un constructo social, atribuible a grupos identificables que se reconocen, seleccionan y adoptan elementos como un legado para comprender sus raíces. Finalmente, Fontal (2003b) distingue la visión afectivo-simbólico, que apunta al patrimonio compuesto por un conjunto de bienes y valores seleccionados de una cultura específica y que pasan a formar parte de la propiedad simbólica o real de algunos grupos. De esta forma, el patrimonio compone la memoria identitaria, tanto individual como colectiva de las personas, que se determina según las percepciones valóricas de cada comunidad. $\mathrm{La}$ autora igualmente destaca la visión procesual, que consideramos enormemente significativa para esta investigación, de acuerdo con la cual se considera al legado patrimonial como:

un conjunto de hilos que cada generación va heredando de las anteriores, tomando irremediablemente decisiones de conservación, de puesta en valor, de recuperación [...] [donde] cada generación debe sumar su propio legado en tanto que el patrimonio es un proceso vivo, en constante transformación. (Fontal, 2016, p. 416)

Estas visiones extienden el horizonte clásico de lo que una vez significó patrimonio, progresando hacia una definición que considera el contexto social de una comunidad que comprende la trascendencia de conservar, valorar, respetar y aprender sobre su patrimonio próximo. Reconocen otras pautas de construcción de 
la identidad local, regional, nacional e incluso mundial que privilegian escenarios de cohesión social lograda a través de encuentros, relatos y diálogos que unen a las personas involucradas, quienes comparten cierto grupo de bienes y prácticas que los identifica (García, 1994).

La construcción y la preservación del patrimonio realizadas socialmente, necesitan de un enfoque que se ocupe del bien cultural, pero también de la identidad de las personas que integran la red comunal en la que se comparten valores y que se vuelve depositaria de los diversos bienes patrimoniales disponibles en su entorno social. A la consideración de ambas dimensiones pensamos que es necesario sumar un elemento articulador, que observamos desde nuestra óptica como docentes y estudiantes de pedagogía. Nos referirnos al rol de la educación que puede dar cabida en el sistema escolar, a acciones pedagógicas específicas que tiendan a incorporar, paulatinamente, la educación patrimonial en el curriculum educativo nacional.

\section{EDUCACIÓN PATRIMONIAL}

La sola consideración de lo patrimonial como un bien valioso y enriquecedor para la sociedad debiese ser suficiente para permitir que un grupo se identifique y se sienta parte de la construcción de una memoria colectiva, pero no parece serlo. Los diferentes espacios garantizados por la educación formal para la formación de los estudiantes delimitan la situación en la que se encuentra la enseñanza sobre patrimonio, siendo insuficiente las maniobras emprendidas para contribuir globalmente a su valoración, tanto en la formación del alumnado como en la formación del profesorado, razón por la cual, la inclusión y trascendencia de la educación patrimonial se presenta como un desafío valorable para el sistema educativo, pues contribuye al desarrollo íntegro de las personas y de los bienes en sus comunidades.

Las actuales políticas educativas contribuyen, a través de un proceso de permanente atención, a los conocimientos, al desarrollo de las competencias y al fomento de las aptitudes del estudiante, sin embargo, las acciones emprendidas en torno a la educación patrimonial son insuficientes, aunque se entienda que su trato no es exclusivo de una materia específica, ni solo responsabilidad de los Establecimientos Educacionales, sino que de todo un conglomerado de personas a las que se asocia una identidad determinada, a nivel local o nacional.

Para poner en valor los bienes patrimoniales, hacerlos circular y ser reconocidos debe elaborarse un plan formativo que brinde herramientas para la comprensión y difusión del patrimonio, que puede ser en escenarios tanto formales (escuelas y universidades) como informales (centros comunitarios o juntas vecinales). A esta necesidad trata de responder la noción de educación patrimonial - postulada en primera instancia por autores como Antoni Colom, Jaime Sarramona y Gonzalo Vázquez (1998), María Pastor (2004) y Olaia Fontal (2003a) - que implica un proceso sistemático de trabajo y colaboración al poner en primer lugar el conocimiento de los sujetos participantes por sobre el imperio del objeto patrimonial entendido como único bastión de prestigio cultural. A partir de las ideas de Fontal, García (2009, p. 274) define educación patrimonial como: 
un proceso pedagógico centrado en las percepciones, conocimientos y valores que subyacen en una sociedad. De esta manera, el bien patrimonial se convierte en un recurso para el aprendizaje, capaz de conectar al ciudadano con su diversidad cultural y su entorno social. Para ello, es necesario trabajar con los valores culturales locales más próximos a las personas, para luego proyectar los valores universales. El diseño, planificación y ejecución de acciones educativas tendrían como objeto de estudio el diseño de estrategias y recursos educativos centrados en las personas y no en el bien cultural.

De acuerdo con esto, distinguimos la relevancia que podría tener la educación patrimonial para la formación integral de los estudiantes, como actores sociales conscientes de lo que significa el patrimonio en conjunto con el conocimiento, las competencias y los valores necesarios para la conservación de estos bienes. En este aspecto, la educación patrimonial defiende una enseñanza integral que busca fortalecer el desarrollo de la identidad cultural que rodea al establecimiento o comunidad; así mismo, se aboca a estimular el pensamiento crítico y consciente en los estudiantes - y también en los docentes y en los padres y apoderados - sobre el pasado, presente y futuro histórico de su comunidad y de su escuela. De acuerdo con esto, una persona que pueda tomar conciencia de sí misma para desempeñar una función social, reconocerá en la educación patrimonial el vínculo que contribuye a la cohesión ciudadana para la construcción de su memoria histórica. Esta perspectiva de educación patrimonial ha de colaborar en la forma en que convivimos como sociedad, como parte de una voluntad de vivir juntos. El interés por el progreso de la educación hacia una experiencia social compuesta a partir de conocimientos teóricos, prácticos y procedimentales, confirmará la necesidad de vernos como sujetos que aprenden continuamente y que reflexionan sobre la praxis en una comunidad específica.

Con respecto a la educación patrimonial como proceso afectivo-simbólico, en tanto dimensión, "se une de manera indisoluble, y al mismo nivel de significatividad, con el conocimiento conceptual básico del mismo, para así poder garantizar el conocimiento, preservación y transmisión del patrimonio en todas sus dimensiones" (Ibáñez, Fontal y Cuenca, 2015, p. 12). Una educación patrimonial que responda a este proceso, asegurará una formación de calidad para los integrantes de las diversas comunidades, tanto educativas como sociales. Estará al servicio de la ciudadanía, razón por la cual, podrá proporcionarle conocimiento, sentido de preservación y de transmisión del patrimonio con un enfoque en el reconocimiento, respeto, valoración y transmisión de los elementos históricos propios.

Para Ibarra y Ramírez (2014) los aportes de la educación patrimonial a la sociedad, a la ciudadanía y al sistema educativo permiten, en primer lugar, que la comunidad proteja su legado histórico-cultural con ayuda de expertos; en segundo lugar, que pueda entenderse este en términos de las competencias que promueve porque fortalece el sentido crítico, la reflexión y la formación ciudadana; y, por último, que refuerza el desarrollo local a través de la promoción de procesos de construcción de identidad territorial. 
La importancia de integrar a niños y jóvenes estudiantes de todos los niveles educativos como conocedores, gestores y cuidadores del patrimonio nacional, es uno de los puntos clave de la educación patrimonial, puesto que, a través de esta, las personas logran identificarse con la identidad nacional, se inculcan valores claves como el respeto, el mutuo entendimiento y la comprensión, y se amplía en gran manera los conocimientos en cuanto al cuidado de los bienes que estos deben preservar, ejerciendo los roles antes señalados. Así, la educación patrimonial asegurará una ampliación del capital cultural de los estudiantes, contribuyendo a su formación integral para incorporarse a la sociedad.

Es entonces por medio de la educación y del proceso de enseñanza aprendizaje que cada estudiante será capaz de comprender el valor de aquello que le rodea, con la finalidad de consolidar el crecimiento de la sociedad. Incorporar a los actores sociales en la gestión del patrimonio es una prioridad de la educación patrimonial, ya que así puede ser sustentado por la comunidad como un recurso de aprendizaje, por medio del cual el ciudadano, desde su diversidad cultural y entorno social, pueda ser partícipe en la construcción de su propia memoria patrimonial.

Al respecto, García (2009, p. 274) señala que la educación patrimonial es "un proceso pedagógico centrado en las percepciones, conocimientos y valores que subyacen en una sociedad". Por ende, el fomento de los procesos educativos relacionados con el patrimonio a través de metodologías que involucren la participación de la comunidad, que logren incluir su visión, experiencias y contenidos, que aseguren la transmisión de conocimiento conceptual, así como también, el fomento de habilidades y competencias de la ciudadanía, equivaldrá a un proceso de enseñanza aprendizaje significativo y colaborativo. Visto así, la educación se comprende como un desafío continuo, constante y necesario que implica

una estructuración continua de la persona humana, de su conocimiento y sus aptitudes, pero también de su facultad de juicio y acción. Debe permitirle tomar conciencia de sí misma y de su medio ambiente e invitarla a desempeñar su función social en el trabajo y la ciudad. (Delors, 1996, p. 15)

En vista de estas necesidades e inquietudes ya expuestas y del panorama más orgánico que ostenta la educación contemporánea, es de suma urgencia propender a una educación patrimonial al alcance de la comunidad, en particular de la educativa.

Pensando en esto, la Unesco inaugura iniciativas que concentran esfuerzos por promover la conciencia patrimonial, en especial entre los jóvenes, como la Red Pea (Red del Programa de Escuelas Asociadas) que en 1994 puso a disposición de los docentes, materiales educativos para el trabajo en el aula, el que se ha mantenido y ampliado con el tiempo (e.g. Patrimonio Mundial en Manos de Jóvenes)33.

En Chile, al tratarse de un campo emergente, se estima necesaria la creación de programas que promuevan y contribuyan al cambio cultural de la educación,

3 El programa europeo Hereduc (Heritage Education), el primero de su tipo en Europa, contó con un manual práctico para su aplicación y su inclusión en las escuelas, como consta en su página web (N. de las As.). 
para fomentar identidad, diversidad, pertenencia y contexto cultural en los Establecimientos Educacionales (Ibarra y Ramírez, 2014). A partir de 2004 aparecen programas abocados a lo patrimonial como el Programa Patrimonial Educacional (PPE) del Ministerio de Educación (MINEDUC), diseñado en conjunto con la Unesco; a este le siguen en 2006 la Red Patrimonio y Educación y en 2007 una línea de trabajo para elaborar herramientas pedagógicas para potencien actitudes y conocimientos sobre patrimonio e identidad. En 2010 el Ministerio de Educación crea, por medio del Consejo de Monumentos Nacionales (CMN), el Área de Educación y Extensión Patrimonial ${ }^{4}$ para potenciar la red de conocimientos y valoración del pasado en el sistema educativo y en la comunidad.

Se advierte que estas iniciativas son altamente propositivas y que bien encausadas pueden resultar significativas y transformadoras para la educación chilena, no solo dentro de las salas de clases, sino también en el amplio rango de relaciones e intercambios sociales y comunitarios. Para ello, hay que proponer al estudiante, al docente y a la comunidad completa, los conocimientos, las destrezas y los valores para acceder al patrimonio, visto como una herramienta de desarrollo social.

\section{EL PATRIMONIO EN EL CURRICULUM ESCOLAR CHILENO}

Desde que los asuntos patrimoniales se han puesto en circulación para su conocimiento y manejo por parte de un público mayor que desborda el mundo académico, las preocupaciones en el ámbito educativo chileno se han centrado en consolidar propuestas metodológicas que validen la atención al patrimonio en el aula, desde la reflexión y la interacción dialogante entre profesores y alumnos, y que establezcan pautas de recuperación y salvaguarda del patrimonio comunitario y escolar adyacente, además del social.

Las diferentes iniciativas del MINEDUC vinculadas al curriculum nacional, contribuyen a mejorar la calidad de la educación, promueven un cambio que se basa en la comprensión de la identidad local y la puesta en valor del patrimonio educacional, y se plantean como abordajes no solo desde las asignaturas aisladas, sino en forma interdisciplinaria propiciando la integración del curriculum y de sus objetivos de aprendizajes, como también la participación ciudadana y la vida democrática en la escuela (e.g. Proyecto de Innovación Pedagógica: Formación Ciudadana en el Aula 2016-2017 y el material pedagógico Conversemos: Cuaderno Docente N7).Junto con esto, se destaca la importancia de los Objetivos Fundamentales Transversales (OFT) que permiten el encuentro entre lo disciplinar y lo formativo del curriculum para la "formación integral de los estudiantes, contribuyendo al crecimiento y autoafirmación, afianzando una formación ético-valórica, con un pensamiento

4 Hoy esta área del CMN se conoce como Comunidades, Educación y Comunicación y en su página web se señala que su objetivo es "difundir, educar, gestionar rescatar y apoyar el reconocimiento, protección y recuperación de los Monumentos Nacionales" (Gobierno de Chile, 2019). Además, reconoce que la educación es "una herramienta fundamental en la participación de la gestión del patrimonio, activando el compromiso de las comunidades asociadas a los bienes patrimoniales" (Gobierno de Chile, 2019). 
más creativo y [...] desarrollando habilidades para la participación activa como ciudadanos" (Ibarra y Ramírez, 2014, p. 44).

$\mathrm{El}$ intercambio de experiencias, relatos y objetos al que el conjunto de actores de la escuela se somete, configuran la historia y memoria del espacio escolar y contribuye a la comprensión y preservación de su patrimonio. Permitiría consolidar las conexiones entre la educación patrimonial y la formación pedagógica de manera de generar a futuro, espacios de enseñanza aprendizaje multidisciplinarios en el sistema educacional chileno, diseñados por docentes capacitados y atentos a las necesidades patrimoniales de su establecimiento y entorno educativo.

Desde dimensiones pedagógicas, García (2009, p. 276) propone "Conocer, Comprender, Valorar y Actuar" el patrimonio de la escuela, pero para que esto suceda, el primero en educarse debe ser el docente (Ibarra y Ramírez, 2014). En nuestro caso, esto se entiende como una acción fundamental que debe ser recogida e integrada a la FID de la Universidad.

Como grupo de investigación creemos que la creación del Archivos Histórico de la escuela en cuestión, nos reporta una oportunidad para reflexionar sobre nuestro rol como académicos y estudiantes universitarios en torno al valor patrimonial de la historia, memoria y bienes de la escuela. También nos hace preguntarnos cuál es nuestro rol en el sistema educativo, en el entendido que la figura del profesor ha mutado y seguirá haciéndolo en la medida en que se diversifiquen los escenarios sociales, culturales, políticos y educativos en los que nos movemos. Creemos que nos permite vernos como seres integrales que aportamos a la comunidad desde diversos ámbitos de acción; que adquirimos, a raíz de estos contactos socioculturales, responsabilidades y deberes con la comunidad y con nuestros alumnos, que van más allá del despliegue de contenidos y saberes dentro del aula, puesto que nos invitan a explorar junto con ellos los caminos del saber comunitario y de las experiencias personales, nutrientes de un aprendizaje orgánico y situado.

\section{CREACIÓN DEL ARCHIVO HISTÓRICO}

Inicialmente, el objetivo principal de nuestra investigación fue crear un archivo para recuperar la historia y memoria del establecimiento educativo, puesto que este año se aproxima a festejar el centenario (1918-2018), lo que lo transforma en uno de los más antiguos de la región. La celebración de la centuria quiere verse coronada con el rescate y puesta en valor de su patrimonio escolar y del levantamiento de memorias y testimonios de sus ex miembros, para su reconocimiento, principalmente de sus actuales estudiantes, profesores y apoderados, que en alguna medida desconocen detalles de la historia y tradición de la escuela.

La investigación se inicia con un plan metodológico que se relaciona estrechamente con la comunidad educativa que busca recuperar su memoria, así como también con el proceso de conservación relacionado con la persistencia de los contenidos culturales tangibles e intangibles de este grupo cultural particular. La creación del Archivo Histórico se inicia en enero del 2017 a través de procedimientos como el régimen de acopio, la revisión, la sistematización y el inventariado de los documentos existentes en el recinto, además de la difusión del proyecto a la 
comunidad educativa para comprometer su colaboración en cuanto a la entrega o préstamo de material para incorporar al archivo.

El trabajo fue iniciado por 4 integrantes del Grupo Poliana, y, en el año 2018, otros 2 de sus integrantes se sumaron a la tarea. Sus empeños se centraron principalmente en extraer y sistematizar la información contenida en 40 libros de registros escolares que datan de 1927 a 2012, tal como se muestra en la Figura 1.
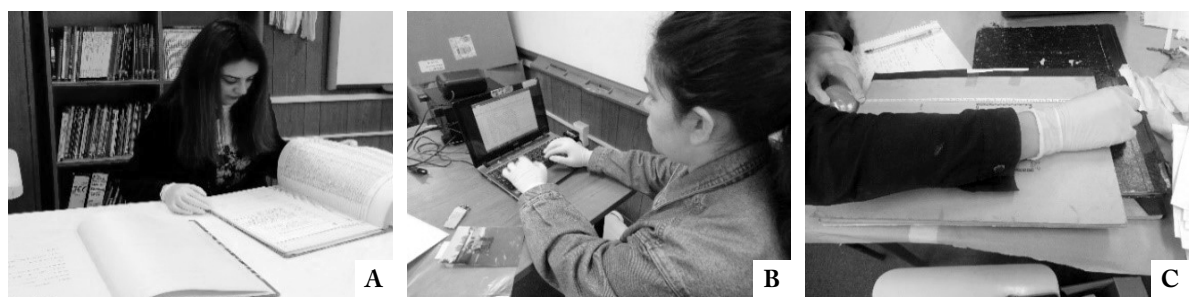

Fuente: Archivo Grupo de Investigación Poliana. Escuela \& Imaginarios.

Figura 1 - Proceso de inventariado de los bienes patrimoniales a alojar en el Archivo Histórico.

De los registros se ha extraído información básica como el total de estudiantes matriculados junto a sus datos personales, el nombre y oficio de padres y apoderados, y la cantidad de alumnos que durante el año escolar eran retirados del establecimiento ${ }^{5}$. En su revisión se han encontrado datos importantes en cuanto a los inicios de la escuela - llamada en un comienzo Escuela Mista (sic.) Rural N60 - cuya matrícula inicial fue de 81 estudiantes, siendo estos de primer y segundo grado. Este número aumentó cada año, sumándose a contar de 1929 el tercer grado de educación, hasta llegar a 1940, cuando se agrega el cuarto grado. Sin embargo, no es hasta 1970 cuando, con un total de 403 pupilos, la escuela comienza a tener una escolaridad básica completa. Aparecen, de igual manera, los contenidos que debían cursar los estudiantes y los talleres que se realizaban, relacionados principalmente con actividades de campo, como, por ejemplo, la mantención del huerto pensando para su propio consumo y que tanto alumnos y profesores debían cuidar.

Al mismo tiempo, muchos alumnos eran retirados del establecimiento debido a que comenzaban a trabajar a temprana edad - en su mayoría a partir de los once años -, hábito del campesinado de la región del Maule como de gran parte de las zonas rurales del país, principalmente durante la primera mitad del siglo XX.

En lo que respecta a los apoderados, se registra la profesión u oficio - consignada en ambos casos como "labores del sexo"-, lo que permite notar, junto con las direcciones de sus viviendas, el cambio producido por la emigración del área rural a la urbana. Al principio, la mayoría trabajaba en oficios relacionados con la

5 Junto a esta información se encontraron rasgos particulares de la ortografía literal que dejan en evidencia la particularidad lingüística de las primeras décadas del siglo XX y su diferencia con los usos actuales, por ejemplo: rejistro o mista (como aparece en el nombre de la escuela) (N. de las As.). 
agricultura y el campo, predominando, en el caso de las mujeres el oficio de dueña de casa, y en el de los hombres, el inquilinaje. Con el paso de los años se sumaban otras labores que permitían conocer el contexto socio-cultural de las familias: comerciantes y cobradores, entre otros. Estos y otros datos reunidos, han sido de gran ayuda para comprender la dinámica de la vida en esta comunidad educativa rural.

Paralelo al trabajo realizado por los estudiantes, la académica coordinadora se dedicó, junto a 4 miembros del grupo, a ordenar y fichar el acervo fotográfico formado por 192 imágenes (todas digitalizadas). Las imágenes en cuestión abarcan los años 1974 a 2017, con algunas excepciones de fotografías obturadas a comienzos del siglo XX (de las que solo se cuentan versiones digitalizadas) que carecen de algún dato que nos permita situarlas en una época específica. Esta labor se aprecia en la Figura 2. Es gracias al escrutinio de las características de la infraestructura - ya que se trata de imágenes del antiguo edificio de la escuela o de sus alrededores - y a la consideración de otros aspectos históricos, sociales y culturales, que podemos concluir su data aproximada.
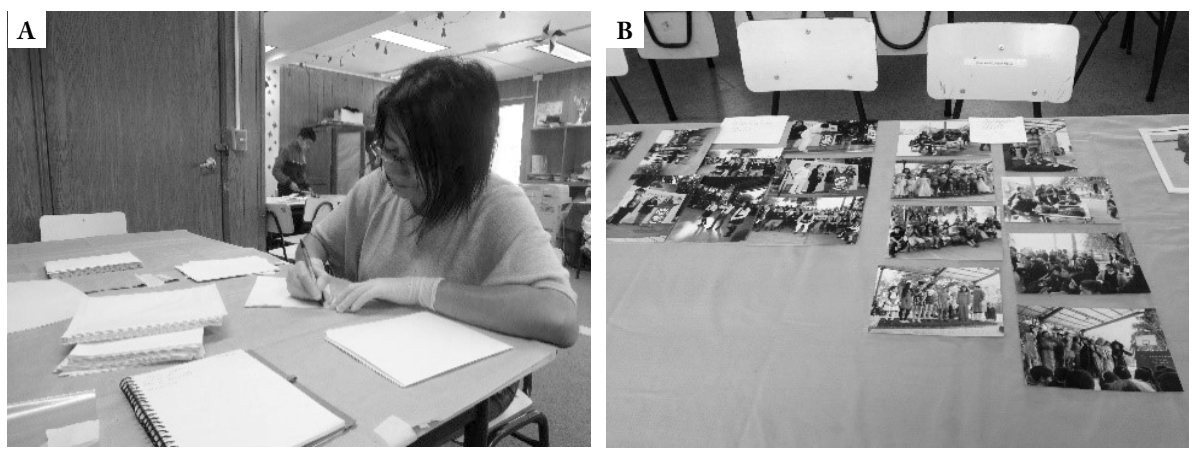

Fuente: Archivo Grupo de Investigación Poliana. Escuela \& Imaginarios.

Figura 2 - Confección de fichas descriptivas de las imágenes fotográficas.

Las imágenes fotográficas retratan distintas actividades escolares, desde ceremonias de licenciatura de kínder y $8^{\circ}$ grado, hasta celebraciones de festividades como la Navidad, de efemérides nacionales como las Fiestas Patrias, paseos de curso, fiestas de despedida (e.g. despedida de uno de sus más emblemáticos directores en 1998), muestras artísticas y distinciones a la familia - como el día de la madre. Se trata de retratos grupales en su mayoría y, en menor medida, de retratos individuales, que han sido agrupados por fechas y, en algunos casos, se ha podido establecer algunas series.

Para enriquecer la aproximación a los bienes patrimoniales de la escuela se realizaron dos sesiones de entrevistas a ex docentes, ex alumnos y ex apoderados del establecimiento, y una recogida de relatos orales, que en total se han llevado a cabo en tres reuniones, que también han servido para socialización los avances del proyecto con la comunidad educativa. Este levantamiento ha sido debidamente transcrito.

Los participantes son quienes han perpetuado su presencia en la escuela a través de nuevas generaciones de estudiantes - hijos e incluso nietos -; colaboran 
participando en actividades extraescolares; ayudan en la emergencia de reparaciones y construcciones que requiera el recinto; comparten experiencias catastróficas (terremotos); rememoran visitas "ilustres" (e.g. el presidente durante la dictadura) y con sus recuerdos apuntan al efecto del paso del tiempo en la fisonomía escolar en sus casi 100 años de existencia.

Tanto en los relatos orales como en las entrevistas, se hace notorio que la mayoría de los alumnos provenientes de espacios rurales eran de familias de escasos recursos, por lo que, para ellos, la escuela era de gran ayuda no solamente en lo educacional, sino también en tanto sostén en las necesidades básicas. Su asentamiento rural derivaba muchas veces en problemas en la calidad de vida de las personas, dificultad en el acceso a servicios básicos, y en la continuidad en el sistema escolar. Tales problemas fueron mencionados por ex estudiantes del establecimiento quienes recordaban la ausencia de locomoción que había (ya entrada la década del 80), o la importancia de la alimentación que se les entregaba cada día.

Con el paso del tiempo los entrevistados y aquellos que relataron sus historias fueron demostrando su interés en colaborar con pequeños datos que aportaban al conocimiento histórico de la escuela, y se han sentido emocionados al saber que se persigue el rescate y recuperación de un espacio que, en algún momento, fue su segundo hogar. La mayoría de ellos ha mencionado que sería muy grato rescatar la infraestructura que existió años atrás: las salas de madera, el salón principal, la casa del ex propietario del terreno, el puente de la entrada, entre otros, considerados patrimonio frágil debido al daño que el último terremoto de 2010 les causó. Los relatos y las entrevistas, en tanto prácticas discursivas, son un material valioso para comprender y conocer la historia de la escuela y de sus actores.

El trabajo realizado ha progresado poco a poco; si bien en un comienzo surgieron inquietudes en torno a la base teórica y práctica desconocida hasta cierto punto, posteriormente se consideraron indispensables para la obtención de resultados efectivos del proyecto ${ }^{6}$. Un apoyo sustancial al desarrollo promisorio del proyecto lo constituyeron los talleres de archivística, conservación, investigación histórica y digitalización cursados en el Centro de Conservación Patrimonial de la Universidad de Talca, que enseñó y reforzó, tanto a los integrantes del Grupo Poliana, como a representantes de la comunidad educativa del establecimiento, a valorar, proteger y conservar los distintos materiales patrimoniales que estaban ya disponibles durante la investigación y aquellos que podían engrosar el archivo escolar.

A contar de nuestra participación en estos talleres, hemos establecido protocolos para preservar los diferentes documentos del archivo. Se han confeccionado sobres de papel libre de ácido para resguardar las imágenes fotográficas, las que también han sido escaneadas para conservarlas digitalmente (copia JPEG y copia maestra TIFF). Se ha procedido de forma similar con los registros escolares, pues

6 Otros integrantes del grupo de investigación se han encargado de investigar los contornos histórico-sociales de la escuela, en tanto su fundación y su marco rural, además de la contingencia propia de la educación del siglo XIX y XX que repercute en el sistema educativo actual, y ordenan datos historiográficos de la escuela y los enmarcan en el contexto local, regional y nacional (N. de las As.). 
han sido guardados en carpetas elaboradas con papel libre de ácido para evitar nuevos daños. Todo el material se almacena en un estante cuyas ventanas han sido cubiertas para que la luz natural y artificial no los afecte. Los relatos orales que se han recopilado se conservan por medio de la transcripción escrita de los audios y también de su digitalización.

Las historias orales y entrevistas, los registros escolares, los documentos y las imágenes fotográficas son nuestros principales recursos para levantar la memoria de la escuela y se han constituido en una excelente excusa para que los miembros de la comunidad educativa se encuentren, compartan sus experiencias y sean conocidos por los actuales integrantes de la escuela y por el Grupo Poliana.

A través de la investigación y el desarrollo de la conservación digital y física del patrimonio escolar, ex estudiantes, ex apoderados y ex funcionarios, junto a los actuales ocupantes del recinto educativo, manifiestan un sentimiento de pertenencia a la escuela; sienten un compromiso por reconstruir la memoria y sus significados culturales. Es así como el patrimonio se vincula indispensablemente con la forma de complicidad en la que interactúan los diversos agentes conformantes de esta identidad social al sentir esta vinculación, así como la relevancia que tiene para resignificar el espacio cultural que les pertenece y que pueden reconstruir a partir de su aprecio y puesta en valor de su patrimonio.

Sin embargo, este trabajo de creación del Archivo Histórico ha despertado en el Grupo Poliana, la reflexión, necesaria y actual en torno a la relevancia que creemos tiene la educación patrimonial vista desde su incorporación en el curriculum educativo nacional. Desde este punto de vista, nuestro propósito inicial de conservación del patrimonio de este establecimiento en particular, se ha ampliado llevándonos a pensar en potenciales acciones pedagógicas que fomenten el conocimiento y la puesta en valor de dicho patrimonio, toda vez que nuestras inquietudes investigativas se vieron recompensadas con resultados gratificantes derivados del escrutinio de los materiales del archivo, con la riqueza mnemónica de los diálogos con los sujetos participantes y del descubrimiento de una oportunidad de crecimiento personal y colectivo para estudiantes y profesores.

\section{EDUCACIÓN PATRIMONIAL Y FORMACIÓN INICIAL DOCENTE}

Una de las aristas de la creación del mencionado archivo es el reconocimiento de la educación rural con relación al patrimonio cultural de la misma, además de sostener los procesos socio-históricos que han conformado a esta comunidad con su propio espacio y su progreso a través del tiempo. Así mismo, la recopilación simbólica realizada a partir de los contenidos culturales ha sido posible debido a la interacción entre ambos elementos que conforman el conocimiento arqueológico y los descubrimientos históricos que preservamos virtualmente en la actualidad.

Adicionalmente, las instancias de comunicación intergeneracional entre los miembros de la comunidad educacional de hoy y de ayer que se identificaron como partícipes de esta cultura escolar, constituyeron espacios indispensables para recuperar y perseverar su memoria. 
Con respecto a las visiones descritas por Fontal (2003b, 2016), en nuestro trabajo prevalecen las visiones objetual, monumentalista e bistoricista. En primer lugar, la visión objetual hace referencia a aquellas evidencias o elementos tangibles del patrimonio - en nuestro caso, los libros de registro, fotografías, y documentos, puesto que hacen alusión a la historia de la escuela, junto con su infraestructura, que ha cambiado a través del tiempo. En segundo lugar, la visión monumentalista se refiere a los bienes patrimoniales que consten o necesiten gran presencia, lo que ocurre con el puente y la base de cemento de la bandera, ubicados ambos en el lado sur del establecimiento, los que se quiere recuperar y conservar para las futuras generaciones; lo mismo ocurre con la edificación actual que alberga las salas y demás dependencias de la escuela, que luego del terremoto del $27 \mathrm{~F}$ se ha reconstruido, pero cuya construcción no responde al imaginario común de la comunidad escolar que aún recuerda el antiguo y emblemático edificio. En tercer lugar, la visión bistoricista - que constituye la base para nuestra indagación sobre educación patrimonial - , se identifica con el peso y el valor que la comunidad educativa le otorga a su propia historia. A estos enfoques se agrega un punto de vista procesual que señala que a través de la investigación se desprende el legado de las distintas generaciones que han construido la memoria de la escuela. A partir de esto, y desde nuestra óptica, estas visiones comprenden la mayoría de las dimensiones del patrimonio que predominan en nuestro proyecto de investigación y en la creación del Archivo Histórico.

En consecuencia, creemos que se han ido conformando, de manera germinal, intereses que circundan procesos de educación pedagógica patrimonial en los estudiantes de Pedagogía en Lengua Castellana y Comunicación de la Universidad Católica del Maule (UCM) y, en especial, en aquellos que integran el grupo, conforme a los conocimientos y habilidades en relación al establecimiento, creando vínculos entre los actores sociales que conforman la comunidad educativa para que sean parte del proceso de develar el contenido patrimonial que se ha estado conservando, en conjunto con el contenido histórico. La finalidad es reconstruir el espacio cultural propio con la finalidad de "preservarlo y estimular la comprensión, tolerancia y respeto intercultural” (Godoy, Hernández y Adán, 2003, p. 26). Es en este punto en el que radica la importancia de la educación patrimonial para nuestro proyecto, puesto que, para la reconstrucción de la memoria cultural colectiva de la escuela, es necesario que los integrantes de su comunidad reconozcan previamente su patrimonio y eso se logra en la medida en que este patrimonio responde a la identidad e historia en la cual los sujetos se reconocen y forman parte. Desde esta perspectiva el Grupo Poliana busca construir bases para incorporar nociones de educación patrimonial en la formación docente universitaria.

A partir de esta experiencia de ejecución del archivo y de las potencialidades de esta investigación, la pregunta es cómo integrar a los conocimientos y saberes exigidos a los estudiantes de FID la tarea de consolidar espacios curriculares transversales para la valoración del patrimonio una vez que ejerzan como profesores. Para ello debemos situarnos en nuestro ámbito de formación profesional y pensar en las dimensiones señaladas por García (2009) y en el plano de actuación educativa universitaria en el que nos encontramos; desde ese lugar podemos incentivar la 
educación patrimonial involucrando diversas áreas del saber académico. La interrogante remite a lo que se puede llegar a emprender en materia educativa desde la Universidad para que nuestros estudiantes cuenten con competencias básicas a elevadas en educación patrimonial.

En primera instancia, pensamos en que la malla de la Carrera puede ofrecer espacios formales que deben ser utilizados en pos de este objetivo, ya sea a través de algunos módulos específicos o de la posibilidad de plantear nuevos módulos en virtud del rediseño curricular que se plantee a futuro. De la misma forma, el eje de prácticas progresivas podría beneficiar a los estudiantes si se abre a materias sensibles de tratar como la educación patrimonial. Si pensamos de forma más ambiciosa, en educación continua o en postgrado, la oferta podría ampliarse con la creación de diplomados y programas de magíster dedicados a un campo de investigación, acción y conocimiento que tiende a observarse como disperso, aglutinante de metodologías y procederes teóricos enfocados en la problemática patrimonial, no obstante, es un ámbito que ha ido ganado terreno y del cual muchas veces se ignora que goza de robustez, puesto que concentra una mirada transdisciplinaria de investigadores, profesionales, profesores y estudiantes de diferentes vertientes.

En segunda instancia, el curriculum de Formación General de la UCM imparte una serie de cursos electivos a través del Plan Electivo de Formación General conocido también como Certificaciones orientadas a promover competencias en áreas del conocimiento, distintas a las ofrecidas en la carrera del estudiante, apuntando "al desarrollo integral de la persona" (Universidad Católica del Maule, 2020). Estos podrían constituirse en una plataforma institucional para transverzalizar los principios de la educación patrimonial a toda la Comunidad Universitaria, como espacios que sensibilicen y capaciten a todos los estudiantes en el tema patrimonial y cultural dado que es un asunto concerniente a toda la ciudadanía. Si bien se trata de módulos complementarios a lo disciplinar, deben ser tenidos en cuenta como un espacio adjunto al que curricularmente se pueda asegurar en una carrera de FID.

La creación del grupo de investigación ha sido el punto de inflexión para un trabajo organizado, colaborativo y dialogante entre académicos y estudiantes. A partir de su constitución, no solo se programaron las jornadas de trabajo con los registros escolares y con el acervo fotográfico de la Escuela; las reuniones con ex alumnos y ex apoderados de la misma y los talleres de archivística, conservación, digitalización e investigación histórica. También fue la punta de lanza de la exposición de las reflexiones, tanto de los estudiantes como de la docente coordinadora, en actividades académicas que nos han brindado la oportunidad de difundir algunos de nuestros avances.

Confiamos que estos primeros pasos nos guiarán en la futura y adecuada definición de acciones pedagógicas patrimoniales concretas y su posterior despliegue.

\section{CONCLUSIONES}

Retomando la idea de García (1994) sobre el metalenguaje del patrimonio, este no se presenta como un cúmulo de expresiones muertas de la cultura, por 
el contrario, se ha comenzado a comprender que su uso depende de lo que nos significan aquellos bienes y de lo que construimos con ellos como memoria e identidad para el futuro.

El proceso de creación del Archivo Histórico de la escuela básica de la ciudad de Talca (Chile) no se trata de un tema que concierne solo al centro educativo y a sus más cercanos. La preocupación del Grupo de Investigación Poliana. Escuela \& Imaginarios es que los estudiantes de FID lleven consigo, una vez egresados, herramientas que le permitan integrarse a la comunidad educativa y social en sus lugares de trabajo como agentes promotores de cambios en torno a materias trascendentales que vislumbren valor y aprecio por el patrimonio. Específicamente, en el espacio escolar, deberán impulsar, cuando no existan, acciones destinadas a levantar, cuidar y difundir los bienes materiales e inmateriales que conforman sus bienes patrimoniales. Su irremediable pérdida o deterioro puede significar un menoscabo de la memoria escolar que debe ser restablecida no solo a favor de los estudiantes, sino también del total de los miembros de la comunidad educativa, formada por los padres y apoderados, profesores, asistentes de la educación, ex alumnos y ex padres $y$ apoderados, y pensando en su puesta en valor frente a la sociedad.

Los esfuerzos que como grupo hagamos luego de estas reflexiones, deben ser sistematizados e incorporados a la FID de los estudiantes de Lengua Castellana y Comunicación - y a futuro de estudiantes de otras carreras de pedagogía y de formación general de la UCM y en un largo plazo a otras casas de estudios superiores - quienes deben desarrollar, en colaboración con los académicos, metodologías y actividades que les permitan acercarse a las cuestiones patrimoniales, entendiendo que la noción de patrimonio involucra expresiones y bienes que deben suscitar el interés de todos, como ciudadanos que somos. De esta forma, se comprenderá que el cuidado del patrimonio es una responsabilidad compartida y que demanda atención no solo de los profesores, sino de cualquier sujeto, independiente de su formación (técnica o profesional), que debe ser inoculado desde los primeros años de escolarización. Transversalizar la importancia del patrimonio en la sociedad, a través de la escuela, ayudará a generar sensibilidad y aprecio por los componentes culturales del país encada uno de sus habitantes.

El Grupo Poliana reconoce que el patrimonio es relevante para la sociedad debido a que las principales propuestas de su trabajo investigativo desarrollado se relacionan con la necesidad de la persistencia de la memoria presente en la comunidad educativa, en la que sus integrantes se reconocen como responsables de una identidad local que valoran y conservan a través de sus bienes patrimoniales.

Estas preocupaciones se relacionan con las acciones pedagógicas patrimoniales es que se consideran necesarias de incluir dentro de los procesos de enseñanza aprendizaje de la FID, pensando en el beneficio que esto significará para el currículum nacional, ya que hasta el momento la temática patrimonial se ha tratado de forma aislada y en espacios más bien informales, aunque en el ámbito escolar. Su trascendencia en el mundo educacional, dependerá de la transmisión de aprendizajes en ámbitos sociales diversos y en trabajo colaborativos con la comunidad social y educativa. 
Entendida como un proceso de aprendizaje que promueve el conocimiento, el sentido crítico, la formación ciudadana, además de la valoración, el rescate y la preservación del patrimonio, la educación patrimonial debe ser incluida en actividades educacionales que consideren el contexto social y local, para que pueda ser reconocida e incorporada en el currículum educativo chileno.

Como grupo de investigación, y por medio de las actividades derivadas de la creación del Archivo Histórico, el grupo de investigación ha adquirido un aprendizaje significativo, hemos entendido el valor de lo material e inmaterial de la Escuela, hemos comprendido el cuidado, resguardo y manejo que debemos tener con aquellos bienes que forman parte de su patrimonio, pues con esta conciencia creemos que las acciones educativas patrimoniales articuladas podrán permanecer en el tiempo.

Confiamos en que iniciativas como la nuestra puedan significar que los futuros profesores presenten a sus alumnos su propia imagen a imitar de un ciudadano preocupado y responsable, consciente de su entorno y de sus necesidades, interesado en el rescate de la historia local y personal de ellos y de sus familias, de sus bienes patrimoniales y de la importancia de su conservación y cuidado. Lo mismo debemos hacer los académicos que junto a ellos nos sumamos a esta significativa tarea.

\section{REFERENCIAS}

CHILE. Ministerio de Educación. Ley no 20.903. Crea el Sistema de Desarrollo Profesional Docente y modifica otras normas, 2016. Disponible en: https://www.bcn. cl/leychile/navegar?idNorma=1087343. Acceso en: 9 mar. 2019.

COLOM, A.; SARRAMONA, J.; VÁZQUEZ, G. Educación no formal. Barcelona: Ariel, 1998.

DELORS, J. La educación o la utopía necesaria. In: ORGANIZACIÓN DE LAS NACIONES UNIDAS PARA LA EDUCACIÓN,LA CIENCIA Y LA CULTURA (UNESCO) (org.). La educación encierra un tesoro. Santiago: Santillana Ediciones UNESCO, 1996.

FONTAL, O. La educación patrimonial: definición de un modelo integral y diseño de sensibilización. 2003. Tesis (Doctoral) - Universidad de Oviedo, Oviedo, 2003a.

FONTAL, O. La educación patrimonial: teoría y práctica en el aula, el museo e Internet. Gijón: Ediciones Trea, 2003b.

FONTAL, O. Educación patrimonial: retrospectiva y prospectivas para la próxima década. Estudios Pedagógicos, Valdivia, v. 42, n. 2, p. 415-436, 2016. https://doi. org/10.4067/S0718-07052016000200024

GARCÍA, N. ¿Quiénes usan el patrimonio? Políticas culturales y participación social. In: CAMA, J.; WITKER, R. (org.). Memorias del Simposio Patrimonio y Política Cultural para el siglo XXI. México: Instituto Nacional de Antropología e Historia, 1994. p. 51-68. 
GARCÍA, Z. ¿Cómo acercar los bienes patrimoniales a los ciudadanos? Educación Patrimonial, un campo emergente en la gestión del patrimonio cultural. Pasos, La Laguna, v. 7, n. 2, p. 271-280, sept. 2009. Disponible en: http://pasosonline.org/ Publicados/7209/PS0209_9.pdf. Acceso en: 29 jul. 2019. https://doi.org/10.25145/j. pasos.2009.07.019

GOBIERNO DE CHILE. Consejo de Monumentos Nacionales. Comunidades, educación y comunicación. Santiago: Consejo de Monumentos Nacionales de Chile, [s.d.]. Disponible en: http://www.monumentos.cl/acerca/areas/comunidadeseducacion-comunicacion. Acceso em: 29 jul. 2019.

GODOY,M.; HERNÁNDEZ,J.; ADÁN, L. Educación patrimonial desde el museo: iniciativas de promoción y puesta en valor del patrimonio cultural en la $\mathrm{X}$ región. Conserva, Santiago, n. 7, p.23-36, 2003. Disponible en: http://www.patrimoniocultural. gob.cl/dinamicas/DocAdjunto_94.pdf. Acceso en: 29 jun. 2020.

HERNÁNDEZ, F. El patrimonio como recurso en la enseñanza de las Ciencias Sociales. In: BALLESTEROS, E. (org.). El patrimonio y la didáctica de las ciencias sociales. La Mancha: Ediciones de la Universidad de Castilla-La Mancha y Asociación Universitaria de Profesores de Didáctica de las Ciencias Sociales, 2003.

IBÁÑEZ, A.; FONTAL, O.; CUENCA, J. Actualidad y tendencias en Educación patrimonial. Educatio Siglo XXI, Murcia, v. 33, n. 1, p. 11-14, 2015. Disponible en: http://revistas.um.es/educatio/article/view/222471/174721. Acceso en: 29 jun. 2019. IBARRA, M.; RAMÍREZ, C. Educación patrimonial en Chile. Una propuesta para el desarrollo de la identidad local. Revista América Patrimonio, Tarapacá, n. 6, p. 37-47, 2014. MATSUURA, K. Prefacio por el Director General de la UNESCO. Tributo al(a) maestro(a) de aula: precursores de la educación del Patrimonio Mundial. In: ORGANIZACIÓN DE LAS NACIONES UNIDAS PARA LA EDUCACIÓN, LA CIENCIA Y LA CULTURA (UNESCO) (org.). Patrimonio Mundial en Manos de Jóvenes. Santiago: UNESCO, 2005 . p. 3-4.

MONFORT, N. L'ús didàctic i el valor educatiu del patrimoni cultural. Barcelona: Universidad Autónoma de Barcelona, 2007.

ORGANIZACIÓN DE LAS NACIONES UNIDAS PARA LA EDUCACIÓN, LA CIENCIA Y LA CULTURA (UNESCO). Convención para la Salvaguarda del Patrimonio Cultural Inmaterial. UNESCO, 2003. Disponible en: http://unesdoc. unesco.org/images//0013/001325/132540s.pdf. Acceso en: 9 mar. 2019.

ORGANIZACIÓN DE LAS NACIONES UNIDAS PARA LA EDUCACIÓN, LA CIENCIA Y LA CULTURA (UNESCO). Oficina Regional de Educación de la UNESCO para América Latina y el Caribe. Patrimonio inmaterial. UNESCO, 2017. Disponible en: http://www.unesco.org/new/es/santiago/culture/intangible-heritage/.Acceso en: 29 jun. 2019. PASTOR, M. Pedagogía museística: nuevas perspectivas y tendencias actuales. Barcelona: Ariel, 2004.

UNIVERSIDAD CATÓLICA DEL MAULE. Instituto de Estudios Generales. Formación Complementaria. Certificaciones. Maule: Universidad Católica del Maule, [s.d.]. Disponible en: https://certificaciones-eg.ucm.cl/. Acceso en: 10 ene. 2020. 


\section{SOBRE LAS AUTORAS}

LORENa LóPEz Torres es doctora en literaturas y culturas latinoamericanas por la Freie Universität Berlin (Alemania). Profesora de la Universidad Católica del Maule (Chile).

E-mail:1plopez@ucm.cl

María Ignacia Castro Rojas es docente en formación pedagogía en lengua castellana y comunicación por la Universidad Católica del Maule (Chile). E-mail: ignacia82288@gmail.com

Priscila del Pilar López Villegas es docente en formación pedagogía en lengua castellana y comunicación por la Universidad Católica del Maule (Chile). E-mail: lopezvpriscila@gmail.com

Conflictos de interés: Declaramos que no hay conflicto de intereses.

Financiamiento: La investigación no cuenta con financiamiento.

Contribuciones de los autores: Administración del Proyecto, Análisis Formal, Conceptualización, Curación de datos, Investigación, Metodología, Escrita - Primera Redacción: López, L.; Castro, M.; López, P. Escrita - Revisión y edición: López, L.

Recibido el 26 de mayo de 2020 Aprobado el 24 de agosto de 2020 